\title{
INVESTIMENTO RECENTE, CAPACITAÇÃO TECNOLÓGICA E COMPETITIVIDADE
}

\author{
Suely Muniz \\ Economista, Pesquisadora do Instituto de Pesquisas Tecnológicas
}

\begin{abstract}
Resumo: A intensificação da concorrência internacional e a difusão de setores econômicos ligados ao complexo microeletrônico têm demandado uma ampliação dos esforços institucionais, tecnológicos e organizacionais por parte de empresas e nações. Tais esforços são cumulativos e ancoram-se em processos de aprendizagens contínuos que são decisivos para a elevação da capacidade competitiva das empresas e nações e, portanto, para o crescimento econômico. No Brasil, entretanto, os investimentos ainda dirigem-se sobretudo para o "saber produzir", enquanto aqueles destinados à formação de ativos complementares, como a elevação da capacitação tecnológica para projetar e desenvolver produtos e processos, são absolutamente insuficientes. Os desafios contemporâneos tornam imperiosas não apenas políticas industriais e tecnológicas, mas também, e sobretudo, uma nova inserção ativa e soberana da economia brasileira na nova dinâmica econômica internacional. Palavras-chave: inovação tecnológica; investimento e produção industrial.
\end{abstract}

A competitividade de um país baseia-se não somente na competitividade das suas empresas, mas também na eficiência do conjunto da sua estrutura produtiva, na qualidade da sua infra-estrutura tecnológica e nas inter-relações entre as partes do sistema de produção. As "externalidades tecnológicas" favorecem os esforços próprios das empresas, elevando a qualidade de suas escolhas. Competitividades em âmbito macro e microeconômico são, portanto, complementares. Neste sentido, a tecnologia é capaz de alterar as vantagens comparativas das nações (e das suas empresas) e as suas possibilidades de inserção na economia mundial, particularmente nos momentos em que se difundem novas tecnologias de base. Essas vantagens não são dadas e estáticas, mas evoluem e requerem, portanto, um esforço de aprendizado tecnológico e organizacional contínuo.

O desenvolvimento tecnológico apresenta hoje, ainda mais do que em épocas anteriores, imenso desafio para os países de industrialização tardia. Se no padrão anterior a tecnologia era basicamente incorporada nas máquinas e equipamentos e os países em desenvolvimento podiam acessá-la através das importações e dos contratos de licenciamento de tecnologia, atualmente esse acesso tornou-se muito mais complexo e especializado. Portanto, diferentemente do que se acreditou por muito tempo no Brasil, para a difusão das novas tecnologias não basta elevar a taxa de investimento em capital fixo e adquirir capacitação para operá-lo eficientemente.

$\mathrm{Na}$ verdade, a difusão tecnológica ocorre através de um processo incremental e contínuo de mudança tecnológi$c a$, que promove a adaptação da inovação original a um sem-número de situações e o aperfeiçoamento contínuo das suas características e desempenho. A rigor, as inovações continuariam ocorrendo durante o processo de difusão e estes não deveriam, portanto, ser vistos como processos independentes (Dosi, 1988; Nelson, 1992).

Dessa maneira, empresas e nações têm conduzido árduo esforço para elevar sua capacitação para produzir com elevada eficiência e, também, sua capacitação para inovar, entendida esta como o conjunto de atividades voltadas para o desenvolvimento e absorção das novas tecnologias. Esta última não ocorreria automaticamente com a elevação da primeira. Ao contrário, a capacitação para inovar terse-ia tornado uma atividade que, pelo elevado conteúdo de conhecimento especializado, demanda ações, investimentos, habilidades, experiências, equipes e inter-relações voltadas especialmente para a geração e a gestão da mudança tecnológica. Isto não quer dizer, entretanto, que essa atividade ocorre de modo estanque, em paralelo à atividade da produção. As sinergias, quer sejam com as equipes de produção, quer entre as equipes especializadas em produtos ou linhas de produtos, são altamente benéficas para a geração de melhorias contínuas de produtos e processos. 
Nesse sentido, a distinção feita por Bell e Pavitt (1993) entre os conceitos de mudança tecnológica e acumulação tecnológica (ou aprendizado tecnológico) é particularmente relevante para a compreensão da dinâmica industrial dos países em desenvolvimento. Enquanto a primeira diz respeito aos processos de incorporação de novas tecnologias à produção, a segunda trata dos recursos voltados especificamente para o fortalecimento da capacitação tecnológica e organizacional. Tal distinção importa na medida em que permite compreender que o investimento físico deve ser complementado por investimentos intangíveis, caso pretenda-se a sustentação da capacidade de produção eficiente ao longo do tempo. As empresas líderes, nas indústrias mais dinâmicas dos países industrializados, estariam realizando dispêndio com "intangíveis" superior ao investimento em bens tangíveis (Nelson, 1992; Bell e Pavitt, 1993). Entre os intangíveis destacam-se: investimento em tecnologia (aquisição e desenvolvimento de conhecimentos próprios e competências necessárias para introdução de novos produtos e processos ou sua melhoria, compreendendo $P \& D$ e engenharia não rotineira); investimento em qualificação (treinamento, organização e estrutura de informações); e softwares.

Muitos autores têm verificado que a capacitação tecnológica evolui de forma diferenciada entre os países, ao contrário do esperado pelos ideólogos da liberalização, segundo os quais os países tenderiam a convergir não só na acumulação tecnológica (a "tecnoglobalização"), mas também na performance econômica. Com efeito, em estudo recente, Patel e Pavitt (1998) constataram a existência de padrões de acumulação tecnológica desiguais e divergentes mesmo entre os principais países da OCDE.

\section{EVOLUÇÃO RECENTE DO INVESTIMENTO NO BRASIL}

Durante a "década perdida", o investimento privado e público foram muito baixos, em relação tanto ao ocorrido na década anterior quanto ao montante que seria necessário para a implantação dos "novos setores industriais" resultantes da difusão da microeletrônica. ${ }^{1}$ Ao longo dos anos 80 , a capacidade de financiamento dos investimentos foi drasticamente reduzida em função da brutal transferência de recursos para o exterior, para o pagamento dos serviços da dívida. ${ }^{2}$

O componente estrangeiro do financiamento do investimento, seja sob a forma de empréstimos bancários, seja de investimento direto, reduziu-se, nos anos 80 , a quase zero.
Desta forma, a indústria brasileira entra na década de 90 - quando se acelera a implantação dos setores criados pelo novo paradigma nas economias industrializadas e nos países asiáticos de industrialização recente - com o mesmo perfil herdado dos anos 70 , quando completou a estrutura típica da segunda revolução industrial, através da diversificação da indústria de bens intermediários - celulose e papel e química - de bens de consumo duráveis e de bens de capital.

Nos anos 90, conduziu-se um acentuado processo de abertura comercial e financeira da economia brasileira. A redução acelerada da proteção tarifária e, a partir de 1994, a sobrevalorização cambial induziram à elevação do investimento, apesar das altas taxas de juros. A concorrência dos produtos importados e o acesso a máquinas e equipamentos atualizados tecnologicamente com juros significativamente inferiores aos nacionais constituíram fortes motivadores destes investimentos. Adicionalmente, a elevação do consumo de bens duráveis e de não-duráveis decorrente da estabilização da moeda atraiu investimentos nestas categorias de bens.

Assim, nos últimos anos da década de 90, muitas intenções de investimento foram declaradas, entre as quais uma expressiva participação do capital estrangeiro que retornou ao país com maior expressão após 1994. Somente no Estado de São Paulo ocorreriam mais de 1.330 projetos de investimentos, totalizando aproximadamente US\$ 70 bilhões, segundo dados de cadastro que abrangeu o período de 1996 a 1998, organizado pela Secretaria de Ciência, Tecnologia e Desenvolvimento Econômico.

Teriam tais investimentos a natureza e o volume necessários para sustentar um novo ciclo de crescimento econômico?

\section{CARACTERÍSTICAS DOS INVESTIMENTOS RECENTES}

Uma das principais características do investimento realizado na segunda metade dos anos 90 é a perda de capacidade de atração da indústria de transformação. Com efeito, esta indústria teria tido uma participação de $4,5 \%$ no período de 1971 a 1980 na FBKF (formação bruta de capital fixo) total, caindo para $2 \%$ no período de 1990 a 1994 , para recuperar-se apenas parcialmente em 1995-97, com 3,3\% (Bielschowsky, 1998).

A análise do fluxo de capitais estrangeiros revela, com efeito, que o investimento nos anos 90 tem se dirigido em larga medida para o setor serviços e para as fusões e aqui- 
TABELA 1

Fluxo de Capitais Líquidos Privados

Brasil - 1990-98

\begin{tabular}{|c|c|c|c|c|c|c|c|c|c|}
\hline & & & & & & & & \multicolumn{2}{|c|}{ Em bilhões de dólares } \\
\hline Capitais & 1990 & 1991 & 1992 & 1993 & 1994 & 1995 & 1996 & 1997 & 1998 \\
\hline Fluxo Total de Capitais Privados & 8 & 3 & 14 & 12 & 10 & 33 & 35 & 20 & 17 \\
\hline Investimento Estrangeiro & 0 & 0 & 2 & 1 & 2 & 3 & 10 & 15 & 25 \\
\hline Investimento em Portafólio & 0 & 4 & 14 & 12 & 51 & 12 & 21 & 10 & 17 \\
\hline Outros Investimentos & 7 & -1 & -2 & -1 & -43 & 19 & 4 & -5 & -25 \\
\hline
\end{tabular}

Fonte: IMF (1999); UNCTAD (1998).

sições de empresas. A partir de 1992, a entrada de capitais voltou a ter expressão, em particular o seu componente a curto prazo - o também chamado capital volátil -, que simplesmente saltou de níveis próximos a zero, em 1990, para US\$ 51 bilhões, quando adveio a estabilização da moeda, em 1994 (Tabela 1). A crise mexicana certamente influenciou a queda para US\$ 12 bilhões, assim como a crise asiática terá interferido sobre o montante que permaneceu neste patamar, em 1997, para recuperar-se apenas ligeiramente em 1998.

A parcela de capital internacional que ingressou no país em forma de investimento direto estrangeiro (IDE) somente veio a tornar-se expressiva a partir de 1996, quando foram iniciadas as privatizações das empresas de energia elétrica e, depois, as de telecomunicações e petróleo. Em 1997, o IDE foi de US\$ 15 bilhões e, em 1998, chegou a US\$ 25 bilhões. Em 1999, o IDE teria atingido o recorde da década, alcançando US\$ 30 bilhões, registrando em 2000 valores tão elevados quanto este último.

Entretanto, o fluxo de investimento estrangeiro dirigido à indústria ${ }^{3}$ apresentou inexpressiva elevação no período 1990-96, tendo significado algo entre $13 \%$ e $25 \%$ do IDE. Por outro lado, os serviços absorveram a maior parte dos recursos, representando em torno de $74 \%$ a $84 \%$ do IDE no período mencionado (Laplane e Sarti, 1999). As declarações feitas recentemente pelo presidente da Sobeet - Sociedade Brasileira de Estudos de Empresas Transnacionais e da Globalização Econômica, de que 80\% dos investimentos estrangeiros estão no setor serviços, indicam que este quadro não foi alterado (Folha de S.Paulo, 29/08/2000).

Nos últimos três anos, apenas $25 \%$ do IDE destinou-se à expansão da capacidade, enquanto $75 \%$ dirigiram-se à compra de empresas privadas ou privatizadas, conforme dados da Conferência das Nações Unidas para o Comércio e o Desenvolvimento - UNCTAD (1999). Em 1997, teriam ocorrido 372 casos de fusão, aquisição ou joint venture, dos quais 204 eram de capital estrangeiro e 168 de capital doméstico. Este número total caiu para 350, em 1998, e para 142, em 1999, dos quais 200 e 100 de capital estrangeiro, nestes anos, respectivamente (Lacerda, 1999).

As aquisições de empresas públicas privatizadas teriam absorvido 26\% do IDE líquido, em 1996, e 30\%, em 1997. Ainda segundo dados da UNCTAD (1999), em 1998 as privatizações teriam mantido o patamar, absorvendo $25 \%$ do IDE. Em 1999 este percentual teria sido de 31\%, segundo porta-voz do Banco Central (Folha de S.Paulo, 1999).

Assim, verifica-se que a extraordinária expansão do IDE não se refletiu com a mesma intensidade nas taxas de investimento (17\% do PIB, a preços de 1980, em 1998) porque parcelas expressivas do IDE nortearam-se pelo processo de compra ou fusão de empresas, principalmente aquelas públicas privatizadas, mas também empresas privadas, reduzidas em seu valor pela concorrência desigual que enfrentaram ao longo de quase duas décadas de crise e pela desvalorização cambial ocorrida em janeiro de 1999. O impacto do IDE sobre a indústria de transformação foi reduzido pelo fato de ter-se dirigido principalmente ao setor serviços. Conformou-se, desta maneira, intensa desnacionalização de empresas e de setores econômicos, sem implicar necessariamente ampliação da capacidade produtiva instalada ou implantação de "novos" setores industriais.

A Tabela 2 apresenta indicadores da indústria brasileira que constituem evidências das dificuldades que passaram a envolvê-la após a abertura comercial e financeira e que os investimentos recentes não parecem ter sido capazes de neutralizar.

$\mathrm{O}$ aumento da produtividade na indústria brasileira, na década de 90 , foi reduzido - média anual de $4,1 \%$ no período 1991 a 1998 - quando medido pelo valor adicionado por trabalhador. ${ }^{4}$ Observe-se que as taxas da segunda metade da década foram menores, comparativamente às dos 
TABELA 2

Produtividade da Indústria, Saldo da Balança Comercial e Variação do PIB Brasil - 1990-98

\begin{tabular}{lrcrrr}
\hline & \multirow{2}{*}{$\begin{array}{c}\text { Produtividade } \\
\text { na Indústria (1) } \\
(\%)\end{array}$} & $\begin{array}{c}\text { Saldo da } \\
\text { Balança Comercial } \\
\text { (US\$ milhões) }\end{array}$ & \multicolumn{2}{c}{ Variação do PIB (\%) } \\
\cline { 5 - 6 } & - & 10.753 & $-4,33$ & $-8,73$ \\
\hline 1990 & 2,0 & 10.579 & 1,03 & 0,26 \\
1991 & 12,5 & 15.308 & $-0,54$ & $-4,21$ \\
1992 & 13,3 & 12.938 & 4,92 & 7,01 \\
1993 & 1,0 & 10.440 & 5,85 & 6,73 \\
1994 & $-3,5$ & -3.158 & 4,22 & 1,91 \\
1995 & 0,1 & -5.554 & 2,66 & 3,28 \\
1996 & 5,5 & -8.357 & 3,60 & 5,76 \\
1997 & 0,6 & -6.484 & $-0,12$ & $-1,34$ \\
1998 & - & -1.198 & 0,82 & $-1,66$ \\
1999 & & & & & \\
\hline
\end{tabular}

Fonte: Manzano (2000).

(1) Produtividade medida pelo valor adicionado por trabalhador (elaboração: Fiesp/Ciesp/ Decompi). Inclui indústria da construção civil e serviços industriais de utilidade pública.

primeiros anos. A balança comercial passou a apresentar saldos negativos difíceis de serem revertidos, mesmo após a desvalorização cambial. O produto interno bruto (PIB) apresentou taxa média de crescimento anual de apenas $2,2 \%$ no período 1990-99, sustentado pela atividade agrícola, pois o PIB industrial cresceu no período somente $1,7 \%$.

É forçoso concluir, portanto, que a economia brasileira estaria abrindo um novo século sem conseguir reconfigurar sua estrutura produtiva industrial para os padrões do paradigma microeletrônico, o que implica graves conseqüências em termos de taxas de crescimento da economia, desequilíbrio na balança com o exterior, ${ }^{5}$ vulnerabilidade externa do país, crescimento do emprego e do sistema de ciência e tecnologia que tende, neste contexto, a ter sua importância reduzida.

\section{OS DESAFIOS ÀS EMPRESAS INDUSTRIAIS}

Os desafios postos às empresas de produção industrial, nestas últimas décadas, são imensos e têm como pano de fundo, de um lado, o lento crescimento da economia mundial e, de outro, o sistema financeiro, impondo-lhes, na prática, taxas de rentabilidade referenciais. ${ }^{6}$ Internamente, essas empresas vivem o desafio de uma inovação complexa e sistêmica. São transformações tecnológicas de vulto, conduzidas pela tecnologia de informações e de comunicações, vale dizer, outro paradigma, outra cultura.

Em paralelo, alteram-se, às vezes radicalmente, as formas de organização do trabalho, de realização de P\&D, de relacionamento das funções (P\&D\&E, produção e marketing, por exemplo) no interior da empresa, o fluxo de informações e a lógica da gestão da produção. São alteradas ainda a forma como se relacionam e como se estruturam as várias unidades dos grandes grupos econômicos e a forma como as empresas relacionam-se com outras empresas, grandes ou pequenas, com seus fornecedores, com seus clientes e com o sistema de ciência e tecnologia. Essas mudanças ocorrem acelerada e simultaneamente, porém de forma profundamente heterogênea entre as nações e, no interior das nações, entre setores e, nesses, entre as empresas.

A absorção das tecnologias de informação e de telecomunicações e as novas filosofias de organização da produção e do trabalho contribuem para o sucesso de empresas e nações, porque as qualificam para as novas normas da concorrência que hoje não se baseiam apenas em preço, mas também em qualidade, flexibilidade, prazos, inovação e serviços pós-venda.

Portanto, nos países onde o paradigma microeletrônico difunde-se mais intensamente, dois fenômenos ocorrem: o primeiro é a expansão e consolidação dos "novos setores" e o segundo "é que as inovações nestes poucos setores industriais vão gradual mas sistematicamente difundindo-se através de toda a atividade econômica, inclusive para indústrias que continuamos a tratar como tradicionais ou de baixa tecnologia" (Rosenberg, 1992:74).

Um tecido industrial que incorpora setores com maior grau de complexidade tecnológica (indústrias baseadas em ciência, como as que integram o complexo eletrônico, a fabricação de aviões e alguns segmentos da indústria química como fármacos, biotecnologia, novos materiais) apresenta dinâmica tecnológica e econômica superior, dadas as maiores oportunidades. São indústrias que podem organizar-se através de sistema de produção flexível para alcançar a eficiência operacional (economias de escala e de escopo) e que requerem: organização de seus próprios departamentos de P\&D\&E; coordenação das interfaces entre as diversas atividades (P\&D\&E, produção, marketing, compras, etc.); estabelecimento de vínculos com outras instituições públicas e/ou privadas para acesso à pesquisa básica e aplicada em áreas de conhecimento específicas; e estímulo à inter-relação entre as equipes de P\&D\&E, no caso das empresas com mais de uma unidade, para a realização das inovações incrementais "contínuas".

O foco da atividade tecnológica dessas indústrias "complexas", portanto, não é prioritariamente custo, mas sim o aperfeiçoamento do produto (design, desempenho, etc.), 
que implica desenvolvimento de capacitações próprias e específicas às características da empresa para a realização de inovações incrementais contínuas. Além disso, como estas indústrias apresentam oportunidades tecnológicas elevadas, requerem ainda as chamadas capacitações dinâmicas, que permitem às empresas a constituição de "antenas tecnológicas" destinadas a captar eventuais novas rotas tecnológicas. Em face destes desafios, verificamse entre esse conjunto de indústrias, as mais elevadas necessidades de contratação de engenheiros e cientistas experientes e de constituição de relações com instituições públicas e privadas de pesquisa básica e aplicada (Bell e Pavitt, 1993).

Já os desafios enfrentados pelas indústrias com complexidade tecnológica menor que a desse primeiro conjunto são elevados, porém, evidentemente, menores. As indústrias intensivas em escala, por exemplo, como a automobilística, eletrodoméstica e siderúrgica, demandam elevada capacidade de interação entre as áreas de engenharia da produção, projeto e fornecedores, que constituiriam as fontes principais de desenvolvimento tecnológico desse grupo. A capacidade organizacional para coordenar interações complexas tem, portanto, importância particular para esse conjunto de indústrias.

Para as indústrias tradicionais (têxtil, bebida, mobiliário e alimentar), as principais fontes de aprendizado/acumulação tecnológica seriam: fornecedores de máquinas e, eventualmente, de matérias-primas; learning by doing; $\mathrm{e}$ serviços de consultoria. Portanto, seria menos comum a organização formal de departamentos de P\&D nessas indústrias. Exceto para as empresas que se voltam para os nichos de produtos diferenciados, com elevado valor agregado, a ênfase na organização da produção seria a redução de custos através do aperfeiçoamento das tecnologias de processo e a principal forma de absorção de novas tecnologias seria a aquisição de máquinas e equipamentos de última geração e a competência para operá-los.

\section{PERFIL TECNOLÓGICO E ORGANIZACIONAL ${ }^{7}$}

A análise desenvolvida a seguir procura apreender as características tecnológicas e organizacionais das empresas que investiram nos últimos anos da década de 90, a partir de dados e informações coletadas através de questionários, entrevistas e visitas às instalações fabris. ${ }^{8}$

A Tabela 3 evidencia que $32 \%$ das empresas investiram em novas plantas, enquanto $59 \%$ o fizeram na expansão e/ou reestruturação da produção e em novos produ- tos. Esta característica é determinante para a reduzida geração de empregos observada: o saldo líquido entre empresas que informaram redução e aquelas cujo investimento resultaria em acréscimo do emprego é inexpressivo, de apenas $3 \%$.

TABELA 3

Empresas e Valor do Investimento, segundo Tipos de Investimento Estado de São Paulo - 1996-98

\begin{tabular}{|c|c|c|c|c|c|}
\hline \multirow{2}{*}{$\begin{array}{l}\text { Tipos de } \\
\text { Investimento }\end{array}$} & \multicolumn{2}{|c|}{$\mathrm{N}^{0}$ de Empresas } & \multicolumn{2}{|c|}{ Valor do Investimento (1) } & \multirow{2}{*}{$\begin{array}{l}\text { Valor Médio } \\
\text { (US\$ milhões) }\end{array}$} \\
\hline & Nos Abs. & $\%$ & US\$ milhões & $\%$ & \\
\hline Total & 46 & 100,0 & 8.041 & 100,0 & 174 \\
\hline Planta Nova & 15 & 32,0 & 2.053 & 26,0 & 136 \\
\hline \multicolumn{6}{|c|}{$\begin{array}{l}\text { Expansão e Reestru- } \\
\text { turação da Produção }\end{array}$} \\
\hline e Novos Produtos & 27 & 59,0 & 2.828 & 35,0 & 105 \\
\hline Não Declarado & 4 & 9,0 & 3.160 & 39,0 & 790 \\
\hline
\end{tabular}

Fonte: Pesquisa IPT (1999).

(1) Refere-se ao valor total do investimento independente do seu estágio de realização.

A maior parcela dos investimentos realizados no período 1996-98 (77\% do valor) teve a finalidade de permitir à empresa a produção de novos produtos, enquanto $62 \%$ ( $55 \%$ do valor) objetivaram a reestruturação da produção. O investimento na expansão da produção foi menor, mas, ainda assim, expressivo.

$\mathrm{O}$ investimento mostrou-se extremamente concentrado setorialmente. O setor automobilístico recebeu $41 \%$ dos recursos, os produtos químicos (commodities) ficaram com $24 \%$ e o setor siderúrgico captou $11 \%$.

Enquanto categoria de uso, o grupo de setores produtores de bens duráveis ocupou a primeira posição em valor do investimento (47\%), mas não em número de empresas (25\%), e é liderado pela indústria automobilística. O presente ciclo de modernização da indústria de veículos teria, necessariamente, que ser acompanhado por investimentos na indústria de autopeças, de forma a permitir-lhe acompanhar os requisitos técnicos e de custos da primeira. Incapaz - financeira e tecnologicamente - de realizar essa tarefa, em ambiente de importações favorecidas, elevados juros e de desvalorização cambial, esse setor viveu, no final da década, possivelmente o mais profundo processo de desnacionalização patrimonial da indústria brasileira.

O processo de desnacionalização tende a continuar, também por decorrência da atual dinâmica tecnológica que requer a aproximação de fornecedores e clientes para o trabalho conjunto desde a fase do projeto de novos pro- 
dutos e processos. Tendo em vista que as empresas brasileiras não se tornaram grandes o suficiente para participar ativamente no mercado internacional, não são interlocutoras nos momentos iniciais de projeto de novos modelos dos oligopólios internacionais, que ocorrem, em geral, nos países de origem destes grandes grupos. O exemplo da cadeia automobilística traduz uma lógica implacável: dado que os fornecedores de partes e componentes são definidos ainda na fase de projeto, ser apenas nacional pode significar a exclusão do mercado nessa cadeia produtiva.

Nesse grupo de bens duráveis, o fato novo vincula-se ao investimento em material eletrônico, aparelhos e equipamentos de comunicações, que veio na esteira da privatização das telecomunicações. Seu valor, entretanto, foi inferior a $4 \%$ do total investido pelo conjunto de empresas da amostra. As empresas produzem equipamentos para infra-estrutura em telecomunicações, mas, à exceção de uma delas, estes respondem por reduzida fatia do seu faturamento, que depende fundamentalmente dos aparelhos para telefonia.

A tendência à desnacionalização dos fornecedores de componentes repete-se neste setor, que se caracteriza por elevado grau de complexidade tecnológica, e pela exigência do modelo simultâneo de desenvolvimento de produtos e processos.

Os setores produtores de bens intermediários também tiveram participação expressiva no investimento do período 1996-98 (46\% das empresas e 41\% do montante investido). Já o segmento de não-duráveis se fez representar pela indústria de alimentos e bebidas e indústria têxtil, mas não registrou a presença da indústria de couro e calçados ou de vestuário e o seu investimento médio é reduzido, em especial o da indústria têxtil.

Finalmente, o segmento de bens de capital esteve totalmente ausente da amostra. Nenhuma empresa produtora de máquinas, de máquinas e equipamentos, aparelhos e materiais elétricos ou de fabricação de equipamentos para automação industrial anunciou investimentos e/ou se dispôs a informar sobre eles. Ao que tudo indica, a tendência é a elevação da defasagem tecnológica entre o setor produtor de bens de capital nacional e o do exterior, quando não da extinção, como parece ser o caso do segmento de produtores de equipamentos para automação industrial.

Essa tendência é profundamente grave para a dinâmica industrial brasileira, pois gera a perda dos efeitos positivos do investimento que são, em grande medida, transferidos para fora, via importação de máquinas e equipamentos, partes e peças com elevado conteúdo tecnológico. Não menos grave é a dificuldade em investir que encontram as pequenas e médias empresas neste cenário, uma vez que não possuem recursos financeiros, tampouco outras facilidades para a importação. Desta forma, a indústria não funciona como um sistema construído sobre relações densas e difusoras das novas tecnologias e, nesse sentido, alimentadoras de aprendizados e competências, tal como se observa nas economias industrializadas. Ao contrário, na medida em que não responde às demandas imediatas e em que não há restrições à demanda ao exterior, lamentavelmente, o sistema industrial brasileiro vai se esfacelando. Apresentam bom desempenho somente os setores que podem operar com elevada escala, beneficiando-se, desse modo, o tamanho do mercado interno, mas que não têm a característica de elevada sinergia com os demais setores industriais. ${ }^{9}$

A dificuldade em encontrar parceiros dos quais se possa esperar o cumprimento de prazos, qualidade, etc. mantém elevada a verticalização, mesmo após todo o processo de terceirização que marcou os anos 90 . Neste cenário fica difícil a constituição de redes - forma de relação entre empresas que se difunde juntamente com o paradigma microeletrônico. Em resumo, se, por um lado, os investimentos dos últimos anos da década de 90 traduziram um grande esforço e, efetivamente, tornaram algumas empresas bastante competitivas, sobretudo no mercado interno, por outro, pouco contribuíram para a reconfiguração da estrutura produtiva industrial, a criação de "externalidades tecnológicas" e, em decorrência, para a geração de elevados e sustentáveis ganhos de produtividade.

Quando consultadas sobre a sua estratégia de concorrência (Tabela 4), as empresas revelaram a grande ênfase que estão atribuindo à concorrência baseada na qualidade, seguida pela concorrência em custos: $57 \%$ das empresas definiram que sua concorrência baseia-se em qualidade e $43 \%$ em custos/preços. O que é notável - mas não surpreendente - é o número bastante reduzido de empresas (8\%) declarando a inovação como principal estratégia de concorrência, bem como o número ainda menor (5\%) concorrendo em prazos e em flexibilidade (3\%).

Por que a conduta das empresas brasileiras é tão diferente, em relação à inovação de produtos e processos, das empresas dos países industrializados e asiáticos de industrialização recente? Seguramente não é por desinformação ou incapacidade empresarial, mas sim conseqüência da presença na economia brasileira de um conjunto de fatores que agem como barreiras às atividades inovadoras. ${ }^{10}$ 


\section{TABELA 4}

Número de Empresas, segundo Estratégias de Concorrência Estado de São Paulo - 1999

\begin{tabular}{|c|c|c|c|c|}
\hline \multirow[t]{2}{*}{ Estratégias (1) } & \multicolumn{2}{|c|}{$\begin{array}{c}\text { № de Empresas que } \\
\text { Atribuem Grau } 1\end{array}$} & \multicolumn{2}{|c|}{$\begin{array}{l}N^{0} \text { de Empresas que } \\
\text { Atribuem Graus } 1 \text { e } 2\end{array}$} \\
\hline & $\%$ do Item & $\%$ das Empresas & $\%$ do Item & $\%$ das Empresas \\
\hline Total & 100,00 & - & 100,00 & - \\
\hline Qualidade & 48,84 & 56,76 & 46,84 & 100,00 \\
\hline Custo & 37,21 & 43,24 & 35,44 & 76,68 \\
\hline Inovação & 6,98 & 8,11 & 8,86 & 18,92 \\
\hline Prazo & 4,65 & 5,41 & 6,33 & 13,51 \\
\hline Flexibilidade & 2,33 & 2,70 & 2,53 & 5,41 \\
\hline
\end{tabular}

Fonte: Pesquisa IPT (1999).

(1) Algumas empresas classificaram mais de um item na mesma ordem.

Inegavelmente, o sistema social de produção brasileiro não favorece a que as empresas se lancem a assumir os elevados riscos das atividades inovadoras.

A razão central para o reduzido percentual de empresas inovadoras no Brasil relaciona-se, em larga medida, com a incapacidade da política econômica brasileira para fazer avançar a estrutura produtiva industrial, isto é, para gerar as condições macroeconômicas necessárias à implantação daqueles setores industriais típicos do paradigma microeletrônico, que apresentam as mais elevadas taxas de crescimento, expressão econômica do seu dinamismo tecnológico que produz contínuas inovações de produtos, abrindo novos mercados e ampliando os já existentes. O ritmo de inovações nos "setores antigos" é obviamente menor e refere-se sobretudo aos processos e menos aos produtos.

Também são desfavoráveis às inovações os fatores mais diretamente relacionados à ciência e tecnologia, como o baixo investimento público e privado em pesquisa básica e aplicada, particularmente nas áreas de ponta, em treinamento nas várias engenharias, necessários para a promoção da sinergia e para a redução do risco na área privada. Estas características têm sido apontadas como decorrência da ocupação dos setores com maiores desafios tecnológicos pelas empresas multinacionais, cujas atividades de desenvolvimento tecnológico ainda permanecem, em sua maioria, localizadas em seus países de origem. ${ }^{11} \mathrm{O}$ desenvolvimento tecnológico feito no Brasil (bem como em outros "mercados emergentes") por multinacionais refere-se quase sempre a adaptações dos produtos às condições locais, sejam estas técnicas (clima, matérias-primas, etc.) ou econômicas (celular ou geladeiras com controle digital com funções menos sofisticadas - e mais baratos - que nos países de origem, por exemplo).
Dessa forma, o baixo investimento privado em capacitação tecnológica, lamentavelmente, tornou-se tradição empresarial brasileira. Poucas seriam as empresas brasileiras que teriam passado do estágio de aprender a produzir com eficiência produtos licenciados por empresas estrangeiras, evoluindo para o detalhamento do projeto básico do produto e um número ainda menor teria evoluído para a capacitação no desenvolvimento local do projeto básico do produto.

De fato, ainda hoje, o principal item do investimento é o de aquisição de máquinas e equipamentos, um fenômeno generalizado nas empresas da amostra desta pesquisa (Tabela 5). Quase 77\% das empresas afirmaram que esse foi o item mais importante no investimento realizado (ou em realização). Quando são consideradas também aquelas que indicaram máquinas e equipamentos como o segundo item mais importante, o percentual amplia-se para 95\% das empresas. Esse resultado indica mudança de postura em relação à primeira metade dos anos 90, quando os investimentos foram classificados de "defensivos". Porém, por outro lado, mostra quão incipientes são os investimentos em intangíveis.

TABELA 5

Investimentos Realizados pelas Empresas, por Ordem de Importância, segundo Tipos Estado de São Paulo - 1996-98

Em porcentagem

\begin{tabular}{lccc}
\hline \multirow{2}{*}{ Tipos de Investimento } & \multicolumn{3}{c}{ Ordem de Importância (1) } \\
\cline { 2 - 4 } & $1^{\circ}$ & $2^{\circ}$ & $3^{\circ}$ \\
\hline Máquinas e Equipamentos & 77 & 18 & 3 \\
Instalações e Construção Civil & 13 & 51 & 10 \\
Treinam. e Qualificação de Mão-de-Obra & 13 & 3 & 33 \\
Serviços Cientificos e Tecnológicos & 0 & 13 & 18 \\
Softwares & 3 & 10 & 15 \\
Estudos Técnico-Econômicos & 0 & 3 & 5 \\
Outros & 3 & - & 10 \\
\hline
\end{tabular}

Fonte: Pesquisa IPT (1999).

(1) Algumas empresas classificaram mais de um item na mesma ordem.

O segundo item de investimento mais importante foi o de instalações e construção civil, apontado por $13 \%$ das empresas e indicando que a introdução de novos produtos implicou a necessidade de ampliação do chão de fábrica. Treinamento e qualificação de mão-de-obra foram indicados por igual número de empresas $(13 \%)$ como os mais importantes investimentos, refletindo a necessidade de adaptação da mão-de-obra à tecnologia microeletrônica incorporada às máquinas e equipamentos. 
Serviços científicos e tecnológicos, softwares e estudos técnico-econômicos tiveram inexpressiva participação no investimento do período 1996-98. Há que se considerar, entretanto, o problema de medição do investimento em softwares, cujo valor teria sido muitas vezes incorporado àquele relativo a máquinas e equipamentos, em conseqüência da dificuldade de discriminá-lo, por se tratar de máquinas com elevado grau de automação e integração. Este é o caso típico da indústria de aparelhos eletrônicos.

Entre as empresas que investiram em aquisição de máquinas e equipamentos, cerca de $80 \%$ realizaram parte das aquisições no exterior, das quais $56 \%$ destinaram mais de $50 \%$ do investimento em máquinas adquiridas no mercado externo. Segundo foi possível apreender, máquinaschaves no processo ou que apresentam elevada automação microeletrônica são importadas principalmente da Alemanha ou Suíça, bem como de fabricantes japoneses, como no caso das telecomunicações, enquanto máquinas secundárias ou pouco dotadas em mecanismos microeletrônicos são adquiridas no mercado interno. Essa pesquisa confirma, dessa maneira, o elevado montante do componente importado do investimento em máquinas já diagnosticado em inúmeros estudos.

Quase $80 \%$ das empresas informaram ter realizado, em 1998 , investimentos em P\&D\&E, enquanto $66 \%$ declararam investimento em aquisição de tecnologia (licenciamento) e igual percentual informou investimento em informatização e em treinamento de pessoal. Estes valores revelam, sem dúvida, que a preocupação com a mudança tecnológica está presente entre este seleto grupo de empresas. $\mathrm{O}$ item informação tecnológica não constituiu objeto de inversão por parte de elevado número de empresas $(62 \%)$, mas aquelas que o fizeram apresentam o mais elevado investimento médio.

Entretanto, o detalhamento da atividade de P\&D\&E revela que o maior esforço é em desenvolvimento, com $97 \%$ das empresas fazendo algum tipo de atividade sob esse título. Cerca de $55 \%$ das empresas afirmaram realizar pesquisa aplicada, mas o investimento nesse item concentra-se nas menores faixas, com $51 \%$ das empresas dedicando-lhe menos de 50\% dos recursos em P\&D\&E. O item engenharia não rotineira é praticado por metade das empresas que realizam desenvolvimento de produtos ou processos. $\mathrm{O}$ valor do investimento nesse item situa-se nos menores estratos e pode ser tomado como o indicador do reduzido esforço próprio na definição dos métodos de gestão da produção e do trabalho. As atividades de pesquisa básica são realizadas por $24 \%$ das empre- sas, com maior incidência nas faixas de menores investimentos. ${ }^{12}$

O que é importante salientar desses dados é que, apesar do elevado percentual de empresas buscando a realização de inovações ${ }^{13}$ - mesmo quando sua estratégia não é concorrer via inovações -, seu dispêndio é reduzido e a inovação é, em sua maior parte, de natureza puramente adaptativa.

Apenas 19\% das empresas acreditam que após os investimentos estão em mesmo nível tecnológico que seus concorrentes do exterior, enquanto $78 \%$ consideram-se superiores tecnologicamente aos concorrentes no mercado interno. Aquelas que se situam no primeiro caso (iguais tecnologicamente) são produtoras de commodities, tradicionais exportadoras ou produtora de bem de elevado valor agregado, o caso mais bem-sucedido da indústria brasileira no presente. Estes resultados são compatíveis com as informações obtidas nas entrevistas, de que os empreendimentos das empresas, inclusive as de capital externo, objetivam sobretudo o mercado interno brasileiro e de forma quase marginal o mercado supra-regional (Mercosul), não confirmando, portanto, a propalada contribuição do investimento estrangeiro para o equilíbrio da balança comercial com o exterior.

\section{CONSIDERAÇÕES FINAIS}

A adoção de tecnologias baseadas na microeletrônica volta-se à solução de situações complexas na produção como o rigor no controle de qualidade, a produção diversificada com possibilidade de regulação do tamanho dos lotes, etc. - à aceleração de lead time e à possibilidade de comunicação sem papel com fornecedores e clientes.

É evidente, portanto, que a incorporação do progresso técnico, ou a modernização da empresa, e a busca da eficiência passam hoje por um tipo de ação profundamente mais complexa que a simples incorporação de um equipamento. Trata-se da gestão do saber, que ganha foros de atividade permanente, requerendo o aprendizado tecnológico e organizacional contínuo, uma vez que as situações de mercado e o saber evoluem em permanência.

A literatura que investiga as razões do sucesso das grandes empresas ${ }^{14}$ sugere, assim, que a sobrevivência e o crescimento da empresa no presente requerem uma capacitação dinâmica (Teece e Pisano, 1998), uma atitude de aprendizado dessas novas tecnologias e modos de organização, um aprendizado que não é apenas individual, mas, sobretudo, coletivo, que é cumulativo e, neste sentido, 
condicionado pelos investimentos anteriores das empresas e determinante das suas possibilidades futuras. Um aprendizado que é local, isto é, vivenciado sobretudo por aqueles que concebem e operam o processo produtivo e que, dadas as várias áreas e interfaces, deve ser coordenado, o que significa a exigência de elevada qualificação de quadros diretivos.

As novas tecnologias e os novos modos de organização conferem às empresas não só elevada capacidade de adaptação às oscilações da demanda, mas, também, eficiência dinâmica que lhes permite modificar, ao menos parcialmente, o ambiente em que atuam, em benefício próprio. Ao promover a aceleração de melhorias (inovações) em seus produtos, a elevação da qualidade e a personalização e ao aumentar a variedade e o nível dos serviços prestados, a empresa estará elevando as suas chances de conquistar maiores parcelas do mercado.

Este é o processo pelo qual passam os grupos econômicos internacionais que se reestruturam em escala internacional, realizando não só o investimento na produção, mas também em distribuição, marketing, etc., obedecendo, via de regra, uma lógica de mercados regionais. Entretanto, não existem indícios de que as empresas brasileiras estejam caminhando firmemente nesta direção. Nem mesmo o conjunto das empresas que investiram nos últimos anos da década de 90 permite compor um quadro otimista. As evidências são inúmeras:

- os problemas de financiamento dos investimentos industriais permanecem graves, dadas as elevadas taxas de juros, a reduzida parcela de IDE dirigida para novas plantas e a ausência de vínculos entre o capital financeiro nacional - que preferiu associar-se aos seus parceiros internacionais - e o capital industrial;

- as empresas nacionais estão entre aquelas tipicamente inovadoras, pois poucas integram o complexo microeletrônico ou as demais indústrias dinâmicas, nascidas do novo paradigma;

- o número extremamente reduzido de empresas inovadoras dificulta a ampliação de externalidades tecnológicas que têm forte impacto sobre a produtividade do conjunto da economia: desverticalização da produção e ampliação de redes de empresas; intensificação do vínculo universidades/institutos de pesquisa e empresa; e aprofundamento das atividades de ciência e tecnologia;

- as empresas brasileiras não constituíram grandes grupos privados capazes de tornarem-se players nesta economia internacional desregulamentada, característica esta que conduz a um processo de desnacionalização de alguns segmentos da indústria ou à sua desestruturação;

- em ambiente caracterizado por elevada instabilidade e quase sempre desfavorável às atividades inovativas, a grande maioria dos empresários brasileiros adotou tradicionalmente a estratégia de adquirir tecnologia no mercado, em especial no mercado externo. Para a modernização da gestão da produção, está se repetindo a mesma prática, isto é, "método de gestão" adquire-se no mercado, via compra de softwares padrões. Essa pode ser uma má aposta, pois a capacitação tecnológica e organizacional é firma-específica e de difícil transferência. Ao não buscá-la, através de esforços próprios, as empresas perdem oportunidade para elevar a sua eficiência, produtividade e a competitividade da economia brasileira.

O padrão tecnológico do parque industrial brasileiro, assim, aproxima-se daquele identificado (Pavitt, 1984; Bell e Pavitt, 1993) para as indústrias tradicionais, que têm os fornecedores de máquinas e equipamentos e de matériasprimas como principais fontes de desenvolvimento tecnológico. Os casos de empresas que refletem a complexidade tecnológica das indústrias baseadas em ciência não passam de algumas dezenas, sem fôlego, portanto, para impregnar o tecido industrial.

Diferentemente do ocorrido até os anos 80, o atual padrão tecnológico e organizacional das empresas e da economia brasileira não parece ter força para enfrentar os desafios impostos pelas políticas de desregulamentação e de abertura comercial e financeira implementadas na década de 90. As empresas brasileiras enfrentam agora concorrentes poderosos que acumulam há anos, décadas e, em alguns casos, há mais de século, a capacitação tecnológica e organizacional que lhes permite produção com elevada eficiência ao longo do tempo e, não menos importante, lhes permite fundirem-se a outras e migrarem para os setores mais dinâmicos, em determinadas situações, abandonando aqueles de menores taxas de crescimento e lucros. Essas são, efetivamente, empresas competitivas.

As nossas empresas, mesmo as consideradas competitivas, não encontram condições de oferecer resistência, porque não têm recursos - financeiros, tecnológicos e gerenciais - para garantir a eficiência ao longo do tempo. Se pressionadas por atores do oligopólio internacional, a capitulação é quase imediata. Como estes ex-empresários têm a possibilidade de continuar acumulando riquezas através das aplicações financeiras, não resistem à forma da inserção econômica nacional e à atual política econô- 
mica. Os grandes grupos que permaneceram na atividade industrial tampouco resistem, pois parte de seus rendimentos são não-operacionais, obtidos junto ao mercado financeiro.

Lamentavelmente, os investimentos industriais recentes não parecem ter sido capazes de implantar uma nova estrutura industrial dinâmica que assegurasse uma inserção competitiva da indústria brasileira na economia internacional. Apesar do elevado esforço para a sua realização, por parte de algumas dezenas de empresas, esses investimentos, em termos agregados, foram insuficientes para configurar um padrão tecnológico e organizacional superior, pouco favoreceram a estruturação de relações de novo tipo entre as empresas e entre as empresas e o sistema de ciência e tecnologia, pouco contribuíram para a geração de empregos e, finalmente, pouco colaboraram para o equilíbrio da balança comercial.

\section{NOTAS}

Versão modificada de artigo enviado ao XXI Simpósio de Gestão da Inovação Tecnológica. São Paulo, nov. 2000.

1. A taxa de investimento (\% do PIB a preços de 1980 ) caiu de quase $23 \%$, em 1980, para pouco mais de 15\%, em 1990. Em 1992 cairia abaixo de 14\%.

2. O endividamento contraído por empresas privadas e pelo setor público, durante os anos 70, avolumou-se desmesuradamente com a elevação das taxas de juros norte-americanas a partir de 1979.

3. Compreende indústria extrativa.

4. Esta metodologia que utiliza o valor adicionado e não a produção tem a vantagem de levar em conta o efeito da elevação das importações de insumos industriais no cálculo da produtividade para a indústria brasileira. $\mathrm{O}$ debate sobre as várias metodologias de cálculo da produtividade pode ser visto em Manzano (2000), capítulo 3.

5. Na medida em que a produção de bens do complexo eletrônico, química fina, etc. é internalizada de forma muito incipiente mas que empresas e consumidores finais desejam acesso a esses produtos, onerando as importações de bens com elevado valor agregado.

6. Uma breve análise do domínio da lógica financeira sobre a atividade industrial é feita em Muniz (2000), capítulo 1.

7. Esta seção analisa os resultados de uma pesquisa de campo conduzida por equipe do IPT - Instituto de Pesquisas Tecnológicas, em 1999, com 55 empresas, predominantemente de grande porte, que realizaram investimentos na indústria de transformação paulista, no período 1996-98. Essa amostra de empresas não é estatisticamente representativa do universo industrial brasileiro e por esta razão os resultados quantitativos da pesquisa não devem ser generalizados. Contudo, apresenta informações qualitativas extremamente ricas para a compreensão do presente momento.

8. Os questionários foram respondidos por 46 empresas. Destas, 9 foram também entrevistadas, além das entrevistas com outras 9 empresas. Os detalhes da pesquisa podem ser vistos em Muniz (2000), capítulo 4.

9. Evidentemente esta afirmativa não deve ser entendida de forma absoluta. A indústria automobilística, ao se modernizar, requer a modernização da indústria de vidros, siderúrgica, etc., com as quais tem forte sinergia. O que se quer enfatizar é que o caráter invasivo das indústrias de automação microeletrônica, informática, etc. e o seu efeito sobre a produtividade de todo o sistema são muito superiores.

10. Freqüentemente a explicação oferecida é de que se trata de um problema cultural do empresário brasileiro. Ao tratar a questão como sendo de responsabilidades individuais, isenta a responsabilidade maior da política econômica dos sucessivos governos brasileiros.
11. A respeito da internacionalização das atividades de desenvolvimento tecnológico das grandes empresas, ver Patel e Pavitt (1998) e Patel e Vega (1998).

12. Uma das empresas afirmou ter destinado $100 \%$ dos recursos em P\&D\&E para este fim, o que sugere uma falha no preenchimento do questionário ou um problema de interpretação conceitual.

13. Mesmo quando se amplia o escopo de empresas, esta constatação permanece válida. A Paep apurou, junto à totalidade das empresas industriais paulistas com mais de 50 empregados, que a quantidade de empresas inovadoras é compatível com a encontrada em outras economias, segundo Quadros et alii (1999).

14. Ver Muniz (2000), capítulo 2.

\section{REFERÊNCIAS BIBLIOGRÁFICAS}

BELL, M. e PAVITT, K. "Technological accumulation and industrial growth: contrasts between developed and developing countries". Industrial and Corporate Change, v.2, n.2, 1993, p.157-210.

BIELSCHOWSKY, R. Investimentos na indústria brasileira depois da abertura e do real: o mini-ciclo de modernizações, 1995-97 (www.cepal.org), 1998.

DOSI, G. "The nature of the innovative process". In: DOSI, G. et alii (eds.). Technical change and economic theory. Londres, Pinter Pub., 1988, p.221-238.

FOLHA DE S.PAULO. Caderno Dinheiro, 17/12/99, p.8. Caderno Dinheiro, 29/08/00, p.B14.

INSTITUTO DE PESQUISAS TECNOLÓGICAS - IPT. A dinâmica do investimento industrial em São Paulo e a capacitação tecnológica. São Paulo, 1999 (Relatório Final IPT/DEES n.40.425).

LACERDA, A.C. "Economia brasileira: reestruturação produtiva e vulnerabilidade externa". $13^{\circ}$ Congresso Brasileiro de Economistas. Rio de Janeiro, 1999.

LAPLANE, M. e SARTI, F. Investimento direto estrangeiro e o impacto na balança comercial nos anos 90. Brasília, Ipea, n.629, 1999 (Texto para Discussão).

MANZANO, M.P.F. Liberalização econômica e produtividade no Brasil dos anos 90: impactos sobre o emprego. Tese de Doutorado. Campinas, Instituto de Economia, Universidade Estadual de Campinas, 2000.

MUNIZ, S. Sambando em gelo fino: investimento industrial, capacitação tecnológica e organizacional e competitividade brasileira nos anos 90. Tese de Doutorado. São Paulo, Escola Politécnica, Departamento de Engenharia de Produção, Universidade de São Paulo, 2000.

NELSON, R. "Recent writings on competitiveness: boxing the compass". California Management Review, v.34, n.2, 1992, p.127-37.

PATEL, P. e PAVITT, K. National systems of innovation under strain: the internationalisation of corporate $R \& D$. Sussex, SPRU, 1998 (Electronic Working Papers Series, 22).

PATEL, P. e VEGA, M. Patterns of internationalisation of corporate technology: location versus home country advantages. Sussex, SPRU, 1998 (Electronic Working Papers Series, 08).

PAVITT, K. "Sectoral patterns of technical change: towards a taxonomy and a theory". Research Policy, v.13, 1984, p.343-373.

QUADROS, R. et alii. "Padrões de inovação tecnológica na indústria paulista". São Paulo em Perspectiva. São Paulo, Fundação Seade, v.13, n.1-2, 1999, p.53-66.

ROSENBERG, N. "Science and technology in the twentieth century". In: DOSI, G. et alii. Technology and enterprise in a historical perspective. Nova York, Oxford University Press, 1992, p.63-96.

TEECE, D.J. e PISANO, G. "The dynamic capabilities of firms: an introduction". In: DOSI, G. et alii. (orgs.). Technology, organization and competitiveness. Nova York, Oxford University Press, 1998, p.193-212.

UNITED NATIONS CONFERENCE ON TRADE AND DEVELOPMENT UNCTAD. World investment report 1999: foreign direct investment and the challenge of development. Genebra, United Nations, 1999.

UNITED NATIONS CONFERENCE ON TRADE AND DEVELOPMENT UNCTAD. World investment report 1998: trends and determinants. Genebra, United Nations, 1998. 